\title{
Trauma Surgery $\&$ Acute Care Open \\ Current management of malignant bowel obstructions: a survey of acute care surgeons and surgical oncologists
}

\author{
Josh Bleicher @ ( ,' Laura A Lambert, ${ }^{1,2}$ Courtney L Scaife, ${ }^{1,2}$ Alexander Colonna ${ }^{1}$
}

\begin{abstract}
- Additional supplemental material is published online only. To view, please visit the journal online (http://dx.doi. org/10.1136/tsaco-2021000755)
\end{abstract}

'General Surgery, University of Utah Health, Salt Lake City, Utah, USA

2Surgical Oncology, Huntsman Cancer Institute at the University of Utah, Salt Lake City, Utah, USA

Correspondence to Dr Josh Bleicher; josh.bleicher@ hsc.utah.edu

Received 12 April 2021 Accepted 25 May 2021 (c) Author(s) (or their employer(s)) 2021. Re-use permitted under CC BY-NC. No commercial re-use. See rights and permissions. Published by BMJ.

To cite: Bleicher J, Lambert LA, Scaife $C L$, et al. Trauma Surg Acute Care Open 2021:6:e000755.

\begin{abstract}
Background Malignant small bowel obstructions (MSBOs) are one of the most challenging problems surgeons encounter, and evidence-based treatment recommendations are lacking. We hypothesized that current opinions on MSBO management differ between acute care surgeons (ACSs) and surgical oncologists (SOs).

Methods We developed three case scenarios describing patients with previously treated cancer who developed an MSBO. Each case had five to six alternate scenarios, intended to capture the heterogeneity of MSBO presentations. Members of the Society of Surgical Oncology, the American Society of Peritoneal Surface Malignancies, and the Eastern Association for the Surgery of Trauma were asked how likely they would be to offer surgical treatment in each scenario. Responses were analyzed for factors associated with the likelihood surgeons would offer surgical management.

Results 316 surgeons completed the survey: 119 (37.7\%) SOs and 197 (62.3\%) ACSs. Overall, SOs were nearly twice as likely as ACSs to recommend surgical management. The largest differences between provider groups were seen in patients with an increased metastatic burden. In a patient with MSBO with metastatic colon cancer, both SOs (95.8\%) and ACSs (94.4\%) were likely or very likely to offer an operation ( $p=0.587)$; however, this fell to $91.6 \%$ and $77.7 \%$, respectively, when this patient had multiple hepatic metastases $(p=0.001)$. All surgeons were less likely to offer surgery to patients with multiple sites of obstruction, recurrent MSBO, and shorter disease-free intervals.

Discussion Opinions on MSBO management differ based on surgeon training and experience. Multidisciplinary management of patients with MSBO should be offered when available and increased emphasis placed on determining optimal management guidelines across specialties.

Level of evidence Level IV Epidemiologic.
\end{abstract}

\section{INTRODUCTION}

Malignant small bowel obstructions (MSBOs), occurring in up to $15 \%$ of patients with cancer, are one of the most complex challenges faced by surgeons and their patients. ${ }^{12}$ This often represents a terminal event for oncology patients and no highquality evidence exists to help surgeons determine an optimal therapeutic approach. ${ }^{3}$ Surgical intervention, whether lysis of adhesions, segmental bowel resection with or without reanastomosis, diversion with either an ostomy or venting drain, or surgical bypass is often high risk. When patients have disseminated cancer as the source of their MSBO, 30-day mortality ranges from $0 \%$ to $32 \%$ and morbidity $22 \%$ to $87 \% .{ }^{4}$ Even with successful initial management, recurrent obstruction $(6 \%$ to $47 \%$ ), repeat operations ( $2 \%$ to $15 \%$ ), and readmission rates $(38 \%$ to $74 \%)$ are high. ${ }^{5}$ Patients without disseminated cancer who present with MSBO have much more favorable outcomes after surgery. ${ }^{6}$

The wide range of outcomes after surgery demonstrates the challenge behind decision-making for these patients. MSBO presents in many different ways and the heterogeneous nature of this disease makes study of the problem difficult. The cause of the obstruction can be related to disseminated disease, a single metastatic lesion, or adhesions, and distinguishing between these etiologies preoperatively is not always possible. With multiple different therapeutic options for management of MSBO, including endoscopic, medical, surgical, and palliative care approaches, determining which patients would benefit most from surgery is critical. ${ }^{7}$ Certain clinical factors, such as dependent functional status, older age, presence of ascites, and preoperative nutritional status are associated with poorer surgical outcomes and can therefore be used to help guide decision-making. ${ }^{4} 9$ The effects of other clinical factors on surgical outcomes, such as the type of malignancy, extent of metastatic disease, and patient response to systemic treatment, are less well studied.

Depending on the clinical setting, MSBO is managed by general surgeons and/or different subspecialists, including acute care surgeons, colorectal surgeons, and surgical oncologists. Evidence on differences in management among these different groups of specialists is lacking. We predicted that surgical decision-making for patients with MSBO is influenced by surgeon clinical training and current practice setting. We surveyed acute care and surgical oncology-trained surgeons across the USA to better understand surgeon opinions on operative management of MSBO and to determine whether trends in management based on surgeon factors exist.

\section{METHODS}

\section{Survey development and distribution}

This study is a cross-sectional analysis of surgeon opinions on decision-making and treatment of patients with MSBO. We developed a survey 
consisting of a series of demographic questions and three case scenarios (online supplemental file 1). Demographics included surgeon age, gender, fellowship training, experience, and current practice setting. Surgeons self-reported their current location (by region), rurality (self-described), and practice type (academic vs private).

Each case scenario described a patient with previously treated cancer who subsequently developed a bowel obstruction. All cases described patients that have a complete obstruction that will not resolve without surgery. All patients had no signs of peritonitis or other indications that they need an emergent operation. The patients in all cases are not of advanced age $(45,50$, and 62 years), healthy other than their malignancy, and with good functional status. Preoperative functional status, older age, medical comorbidities, and an emergent indication for surgery have all been previously associated with worse outcomes after surgery. ${ }^{69}$ These factors were intentionally excluded from cases to allow survey respondents to focus on the clinical pathological findings, not individual patient factors.

After presenting each case, surgeons were asked how likely they would be to offer this hypothetical patient an operation using a 5-point Likert scale (1: very unlikely, 2: unlikely, 3: unsure, 4: likely, and 5: very likely). A component of each base scenario was then altered to reflect a change in the type of primary malignancy, the extent of metastatic disease, the length of the disease-free interval, the presence of ascites, or whether this was the patient's first or second episode of obstruction. For each change in the base scenario (five to six per case), surgeons were asked how likely they would be to offer this hypothetical patient an operation. All cases were created with assistance from experts in surgical oncology and acute care surgery, and all cases were pilot tested with a group of surgical oncologists and acute care surgeons and subsequently adjusted based on participant feedback.

We distributed the survey via email to the memberships of the Eastern Association for the Surgery of Trauma, the Society of Surgical Oncology, and the American Society of Peritoneal Surface Malignancies. All currently practicing, US-based, attending surgeon members of these society email registries were included and asked to participate on two occasions. Surgeons participated by completing the survey on REDCap. Surgeons were excluded if they failed to complete the entirety of the first case. If surgeons did not complete the second or third case, the information provided from the first case was included. We did not perform data imputation for missing data. We compared demographic data of respondents who completed the full survey and those who did not complete certain cases and identified no significant differences, decreasing the concern for non-response bias. Surgeons with a current practice in general surgery, trauma, acute care surgery, and/or critical care were classified as acute care surgeons. Similarly, surgeons who reported training in any particular area of surgical oncology, including the treatment of peritoneal surface malignancies, were classified as surgical oncologists. Current surgical practices were categorized similarly.

\section{Data analysis}

Demographic characteristics of surgeons and their practices were analyzed using descriptive statistics. Comparison of acute care surgeons and surgical oncologists was performed using the $\mathrm{X}^{2}$ test. Individual case scenario responses were assessed by dichotomizing responses to surgeons likely to offer the patient an operation (defined as the percentage of surgeons who selected they were 'likely' or 'very likely' to offer an operation for the particular case scenario) and those that were 'unsure,' 'unlikely,' or 'very unlikely' to offer an operation. The means and SDs of individual case scenarios were also calculated. Although ordinal in nature, a Likert scale can be analyzed as interval-level data. ${ }^{10}$ Mean scores and percentages were calculated for individual scenarios, across each case, and across all cases combined. For analysis based on the average response to all scenarios, only the responses of surgeons who completed all survey questions were included.

Univariable analysis, using the $\mathrm{X}^{2}$ test, was performed to assess which surgeon factors were predictive of an increased likelihood of a surgeon offering the patient an operation in each scenario. Results were considered statistically significant if the two-tailed $\mathrm{p}$ values were $<0.05$. Multivariable analysis was performed using a Poisson regression model. This model was selected as it provides rate ratios as the measure of association, which are easier to interpret than ORs. ${ }^{11}$ All variables with a $\mathrm{p}$ value of $<0.20$ on univariable analysis were included in these models. 'Fellowship training' was excluded from multivariable analysis, as this variable is a confounder with the variable 'current surgical practice,' and inclusion of both would cause an overadjustment erroneously decreasing the effect size between surgeon factors and the likelihood of offering a patient an operation..$^{12}$ Finally, we used marginal standardization to demonstrate the adjusted likelihood that surgeons would offer patients an operation in each of the three cases. ${ }^{13}$

Although multiple scenarios across the three cases had similar variables (extent of metastatic disease burden, type of malignancy, etc), the heterogeneous nature of the cases prevented direct comparison of these case factors. Responses to individual scenarios are shown with univariable comparison between surgical oncologists and acute care surgeons. The effect of overarching themes between cases, such as presence of ascites or extent of metastatic disease, could not be directly compared because of the heterogeneity between each scenario. Instead, overall trends are discussed. All statistical analyses were performed using Stata V.15.1 (Stata Corp, College Station, Texas, USA).

\section{RESULTS}

The survey was sent to a total of 3006 potential participants, $379(12.6 \%)$ of whom completed at least a portion of the survey. Sixty-three participants only completed the demographic portion of the survey and were therefore excluded. Of the remaining 316 participants, the median age was 45 years and $75 \%$ were male. Approximately half of the participants were fellowship trained in trauma, critical care, and/or acute care surgery and another third had surgical oncology fellowship training (table 1). As a group, acute care surgeons were significantly younger and had fewer years of clinical experience than surgical oncologists. Of acute care surgeons, $145(73.6 \%)$ practiced both trauma and acute care surgery, $31(15.7 \%)$ practiced acute care surgery alone and $4(2.0 \%)$ practiced trauma surgery alone. Half of the participants had $<10$ years of postgraduate work experience, whereas $72(22.8 \%)$ had been in practice for at least 20 years. Most participants were from academic practices and most practiced in urban settings. Participants practiced in all regions of the USA.

For individual cases, surgeon gender, practice location, practice type (academic vs private), and practice rurality had no significant effect on the patient's likelihood of being offered an operation (table 2). Averaging results across all cases, multivariable analysis showed that surgeons with more than 25 years in practice were more likely to offer operations for $\mathrm{MBO}$ than most other surgeons (table 3). This analysis, which differs from 
Table 1 Characteristics of the surgeon respondents and their current practices, reported as $n(\%)$

\begin{tabular}{|c|c|c|c|c|c|}
\hline Variable & Category & All participants n (\%) & Acute care surgeons ( $n=197)$ & Surgical oncologists $(n=119)$ & $P$ value \\
\hline $\begin{array}{l}\text { Age, years (median, } \\
\text { IQR) }\end{array}$ & & $45(39-53)$ & $43(38-52)$ & $48(42-57)$ & $<0.01$ \\
\hline \multirow[t]{3}{*}{ Gender } & Female & 78 (24.7) & $54(27.4)$ & $24(20.2)$ & 0.25 \\
\hline & Male & $237(75.0)$ & $142(72.1)$ & $95(79.8)$ & \\
\hline & Other & $1(0.3)$ & $1(0.5)$ & 0 & \\
\hline \multirow[t]{4}{*}{ Fellowship training } & None & $26(8.2)$ & $22(11.2)$ & $4(3.4)$ & $<0.01$ \\
\hline & Surgical oncology & $107(33.9)$ & $3(1.5)$ & $104(87.4)$ & \\
\hline & Trauma/acute care & $171(54.1)$ & $170(86.3)$ & $1(0.8)$ & \\
\hline & Other & $12(3.8)$ & $2(1.0)$ & $10(8.4)$ & \\
\hline \multirow[t]{3}{*}{ Current practice } & Surgical oncology & $97(30.7)$ & - & $97(81.5)$ & - \\
\hline & Trauma and/or acute care & $197(62.3)$ & $197(100)$ & - & \\
\hline & Peritoneal surface malignancy & $22(7.0)$ & - & $22(18.5)$ & \\
\hline \multirow[t]{6}{*}{ Years in practice } & $<5$ & $83(26.3)$ & $64(32.5)$ & $19(16.0)$ & $<0.01$ \\
\hline & $5-10$ & $79(25.0)$ & $52(26,4)$ & $27(22.7)$ & \\
\hline & $11-15$ & $42(13.3)$ & $19(9.6)$ & $23(19.3)$ & \\
\hline & $16-20$ & $40(12.7)$ & $24(12.2)$ & $16(13.5)$ & \\
\hline & $21-25$ & $32(10.1)$ & $18(9.1)$ & $14(11.8)$ & \\
\hline & $>25$ & $40(12.7)$ & $20(10.2)$ & $20(16.8)$ & \\
\hline \multirow[t]{4}{*}{ Type of practice } & Academic & $187(59.2)$ & $102(51.8)$ & $85(71.4)$ & $<0.01$ \\
\hline & Private & $50(15.8)$ & $37(18.8)$ & $13(10.9)$ & \\
\hline & Both private and academic & $64(20.3)$ & $47(23.9)$ & $17(14.3)$ & \\
\hline & Other & $15(4.8)$ & $11(5.6)$ & $4(3.4)$ & \\
\hline \multirow[t]{6}{*}{ Location } & Northeast & $71(22.5)$ & $37(18.8)$ & 34 (28.6) & 0.07 \\
\hline & Southeast & $85(26.9)$ & $48(24.4)$ & $37(31.1)$ & \\
\hline & Midwest & $80(25.3)$ & $56(28.4)$ & $24(20.2)$ & \\
\hline & Southern & $24(7.6)$ & $15(7.6)$ & $9(7.6)$ & \\
\hline & Mountain West & $25(7.9)$ & $20(10.2)$ & $5(4.2)$ & \\
\hline & Pacific & $31(9.8)$ & $21(10.7)$ & $10(8.4)$ & \\
\hline \multirow[t]{4}{*}{ Rurality } & Urban & $188(59.5)$ & $113(57.4)$ & $75(63.0)$ & 0.28 \\
\hline & Suburban & $89(28.2)$ & $57(28.9)$ & $32(26.9)$ & \\
\hline & Rural & $32(10.1)$ & $24(12.2)$ & $8(6.7)$ & \\
\hline & Other & $7(2.2)$ & $3(1.5)$ & $4(3.4)$ & \\
\hline
\end{tabular}

the analysis of individual cases, also showed that surgeons in rural settings were more likely to offer patients operations. The surgeon factor that most consistently altered the likelihood a respondent would offer an operation was surgeon specialty.

Across all cases, surgical oncologists were more likely to offer patients an operation than acute care surgeons ( $86.6 \%$ vs $74.1 \%$ for case $1, \mathrm{p}=0.009 ; 50.9 \%$ vs $38.2 \%$ for case $2, \mathrm{p}=0.034$; and $59.5 \%$ vs $40.1 \%$ for case $3, \mathrm{p}=0.002$ ). After adjustment for other surgeon factors with predictive value for each case, this difference in surgical decision-making remained (figure 1). Similar results were found whether surgeon specialty was defined by their fellowship training or their current practice. Decisionmaking of surgeons specializing in the treatment of peritoneal surface malignancies was similar to that of other surgical oncologists across all cases. On multivariable analysis, across all cases, acute care surgeons responded that they would be likely or very likely to offer patients an operation 0.61 times as frequently as surgical oncologists $(\mathrm{p}<0.001)$ (table 3$)$.

An increased burden of metastatic disease had a larger impact on decision-making for acute care surgeons than surgical oncologists. Presence of hepatic metastases did not change decisionmaking for most surgical oncologists for the patient with colon adenocarcinoma $(95.80 \%$ for the base scenario vs $91.60 \%$ with multiple hepatic metastases) or carcinoid tumor (90.99\% for the base scenario vs $87.39 \%$ with hepatic metastases) (table 4). This had a much larger effect on the decisions of acute care surgeons, with larger decreases in the percent of surgeons likely to offer an operation to the patient with colon adenocarcinoma $(94.42 \%$ for the base scenario vs $77.66 \%$ with multiple hepatic metastases) or carcinoid tumor $(79.01 \%$ for the base scenario vs $66.67 \%$ with hepatic metastases). The likelihood of offering an operation was significantly different between specialty groups in the base case with carcinoid tumor $(p=0.008)$ and both cases with hepatic metastases (colon, $\mathrm{p}=0.001$ and carcinoid, $\mathrm{p}<0.001$ ). Surgical oncologists and acute care surgeons also differed on management of patients with MSBO in the presence of pulmonary $(84.87 \%$ vs $63.96 \%, \mathrm{p}<0.001)$ and omental $(78.15 \%$ vs $55.33 \%, \mathrm{p}<0.001)$ metastases from colon adenocarcinoma. The presence of mild ascites in the patient with ovarian epithelial carcinoma led to a similar decrease in the number of respondents likely or very likely to operate for surgical oncologists $(16.07 \%)$ and acute care surgeons (17.98\%), although approximately $25 \%$ more surgical oncologists than acute care surgeons were willing to offer an operation in both scenarios.

All respondents were less likely to offer operations to patients with metastatic pancreatic adenocarcinoma (46.84\%) and 
Table 2 Univariable analysis of factors predictive of participants selecting they would be 'likely' or 'very likely' to offer an operation to the patient in each case

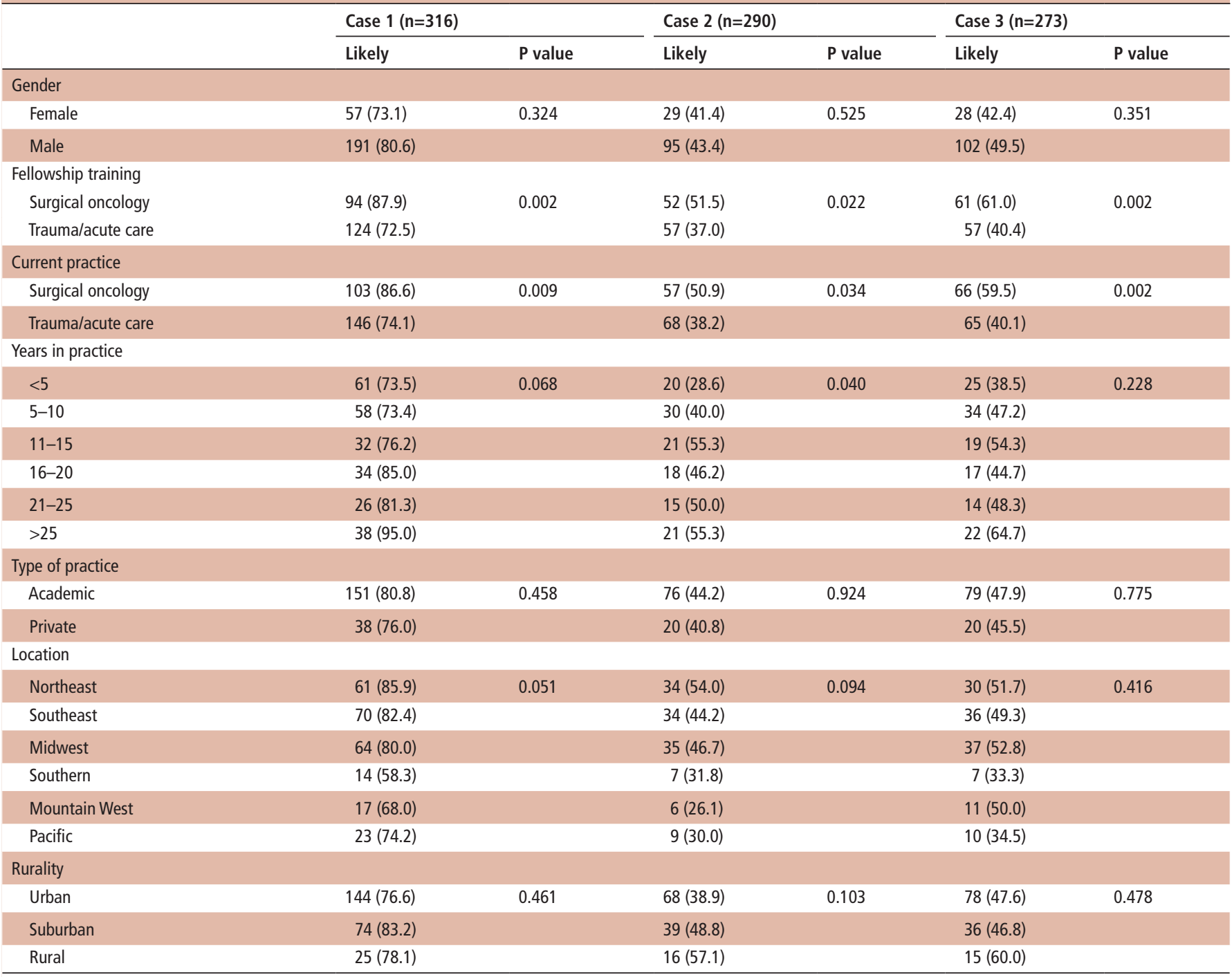

Individual cases were analyzed separately. Participant selections were averaged across all scenarios within each case.

ovarian epithelial carcinoma $(74.48 \%)$ than colon adenocarcinoma $(94.94 \%)$ or carcinoid tumor $(83.88 \%)$ (table 4$)$. Surgical oncologists were significantly more likely to operate in the case scenario of a patient with obstruction secondary to metastatic melanoma (87.5\% vs $64.04 \%, \mathrm{p}<0.001)$. The cases in which all respondents were least likely to offer an operation were those with multiple areas of obstruction $(24.48 \%$ for ovarian epithelial carcinoma and $32.60 \%$ for carcinoid tumor) and cases in which the MSBO represented a second episode of obstruction (24.48\% for ovarian epithelial carcinoma and $44.69 \%$ for carcinoid tumor).

\section{DISCUSSION}

This study confirmed that management of MSBO is highly complex and the decision to offer surgical intervention is dictated by both clinical factors and surgeon factors. The case scenarios created displayed the heterogeneity of this disease process, with a wide variation in responses. For all 17 scenarios, there were surgeons who said they would be 'very likely' and 'very unlikely' to offer patients an operation. The percentage of surgeons who said they would be 'likely' or 'very likely' to offer an operation in each scenario ranged from $22.76 \%$ to $94.94 \%$. We also identified surgeon factors that strongly influenced the likelihood a patient will be offered surgical treatment. Across all cases, surgical oncologists were more likely to offer surgery to patients with MSBO than acute care surgeons. Although this study is based on theoretical patients, and actual patient outcomes with or without an operation are unknowable, this difference in opinions on surgical management of MSBO between specialists points to a difference in practice patterns affecting these patients. This is the first study to identify the importance of surgeon factors in treatment decisions for MSBO.

Prior studies have identified clinical factors that influence outcomes, and therefore decision-making, for patients with MSBO. Age, preoperative nutritional and functional status, low albumin levels, emergent nature of the operation, and the presence of malignant ascites are factors that affect clinical outcomes. ${ }^{4-9} 14$ In one study of patients with disseminated cancer undergoing emergency surgery, patients with a perforation had a 30 -day mortality rate of $34 \%$ and morbidity rate of $67 \% .^{8}$ In the same study, patients undergoing surgery for an obstruction had an 18\% 30-day mortality rate and morbidity rate of $41 \%$. Evidence of peritoneal carcinomatosis is also an independent risk factor for surgical complications. ${ }^{15}$ We identified that surgeons 
Table 3 Univariable and multivariable analysis of factors predictive of participants selecting they would be 'likely' or 'very likely' to offer an operation to the patient in each case; participant selections were averaged across all scenarios across all cases

\begin{tabular}{|c|c|c|c|c|}
\hline & \multicolumn{2}{|c|}{ Univariable } & \multicolumn{2}{|l|}{ Multivariable* } \\
\hline & n (\%) & $P$ value & Incidence rate ratio $(95 \% \mathrm{Cl})$ & $P$ value \\
\hline \multicolumn{5}{|l|}{ Gender } \\
\hline Female & $30(45.5)$ & 0.241 & & \\
\hline Male & $114(55.3)$ & & & \\
\hline \multicolumn{5}{|l|}{ Fellowship training } \\
\hline Surgical oncology & $73(73.0)$ & $<0.001$ & Excludedt & \\
\hline Trauma/acute care & $55(39.0)$ & & & \\
\hline \multicolumn{5}{|l|}{ Current practice } \\
\hline Surgical oncology & $78(70.3)$ & $<0.001$ & Reference & - \\
\hline Trauma/acute care & $67(41.4)$ & & 0.61 (0.49 to 0.76$)$ & $<0.001$ \\
\hline \multicolumn{5}{|l|}{ Years in practice } \\
\hline$<5$ & $27(41.5)$ & 0.001 & 0.66 (0.47 to 0.91$)$ & 0.011 \\
\hline $5-10$ & $32(44.4)$ & & 0.65 (0.48 to 0.89 ) & 0.008 \\
\hline $11-15$ & $25(71.4)$ & & 0.90 (0.68 to 1.19$)$ & 0.462 \\
\hline $16-20$ & $17(44.7)$ & & 0.61 (0.42 to 0.88$)$ & 0.009 \\
\hline $21-25$ & $17(58.6)$ & & 0.78 (0.56 to 1.09$)$ & 0.150 \\
\hline$>25$ & $27(79.4)$ & & Reference & - \\
\hline \multicolumn{5}{|l|}{ Type of practice } \\
\hline Academic & $87(52.7)$ & 0.452 & & \\
\hline Private & $26(59.1)$ & & & \\
\hline \multicolumn{5}{|l|}{ Location } \\
\hline Northeast & $38(65.5)$ & 0.101 & Reference & - \\
\hline Southeast & $39(53.4)$ & & 0.93 (0.70 to 1.22 ) & 0.586 \\
\hline Midwest & $39(55.7)$ & & 1.02 (0.79 to 1.32$)$ & 0.880 \\
\hline Southern & $7(33.3)$ & & 0.59 (0.32 to 1.08$)$ & 0.087 \\
\hline Mountain West & $10(45.5)$ & & $1.06(0.66$ to 1.71$)$ & 0.818 \\
\hline Pacific & $12(41.4)$ & & 0.79 (0.51 to 1.23$)$ & 0.301 \\
\hline \multicolumn{5}{|l|}{ Rurality } \\
\hline Urban & $77(47.0)$ & 0.017 & Reference & - \\
\hline Suburban & $49(63.6)$ & & 1.34 (1.06 to 1.70$)$ & 0.014 \\
\hline Rural & $17(68.0)$ & & 1.56 (1.14 to 2.13$)$ & 0.006 \\
\hline
\end{tabular}

${ }^{*}$ All variables with $p<0.20$ on univariable analysis included in multivariable analysis.

tFellowship training excluded from multivariable analysis as this variable is confounding with the variable describing current practice.

were also less likely to operate on patients with multiple sites of obstruction, recurrent MSBO, and shorter disease-free intervals from their initial surgical treatment. In future studies of patients

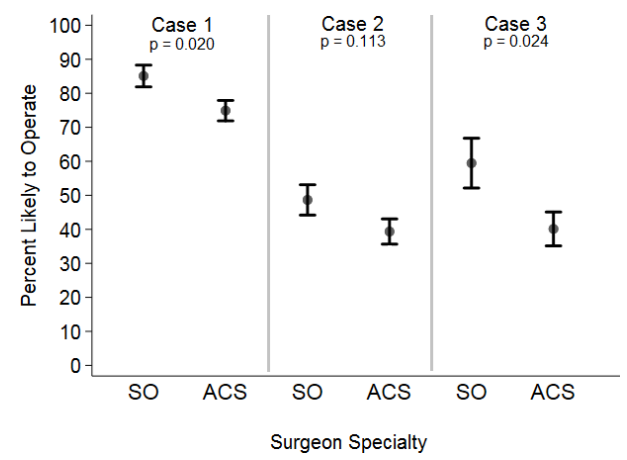

Figure 1 Adjusted rates of participants selecting they would be 'likely' or 'very likely' to offer an operation to the patient in each case, by surgeon specialty. ACS, acute care surgeon; SO, surgical oncologist. with MSBO, these factors should be assessed for their effect on clinical outcomes.

Fear of surgical morbidity and mortality are not the only reason surgeons choose not to offer patients operative intervention for MSBO. Although MSBO is often considered a terminal event regardless of treatment, some population-based studies have shown improved survival for patients managed surgically compared with those managed medically. ${ }^{16} 17$ Concerns over limited quality of life after surgery are also important. The quality of life for patients with MSBO post-surgery is largely unstudied and when it has been studied, the tools used are unvalidated. ${ }^{7}$ A 2016 Cochrane review of MSBO identified no data on quality-of-life scores. ${ }^{4}$ The ability of patients to tolerate oral intake after surgery, time spent out of the hospital, and discharge to home have all been used as surrogate quality-of-life metrics. A systematic review noted that $45 \%$ to $75 \%$ of patients are able to resume an oral diet, $34 \%$ to $87 \%$ of patients are discharged home, and $11 \%$ to $61 \%$ of patient's remaining days alive are spent in the hospital after surgery. ${ }^{5}$ Baddeley et al are undertaking a study to identify a core set of outcomes to measure 
Table 4 Responses to individual case scenarios by practice type

Total Surgical oncologists $\quad$ Acute care surgeons $\quad$ P value

Case 1: a 50-year-old man with colon cancer 36 months from resection and adjuvant chemotherapy with a single point of obstruction in the terminal ileum. He has a single, $3 \mathrm{~cm}$ metastatic lesion in his liver, but no other metastatic disease.

\begin{tabular}{lllll} 
Base scenario & $94.94(4.70 \pm 0.64)$ & $95.80(4.83 \pm 0.48)$ & $94.42(4.62 \pm 0.71)$ & 0.587 \\
\hline Multiple hepatic metastases & $82.91(4.16 \pm 0.97)$ & $91.60(4.48 \pm 0.72)$ & $77.66(3.97 \pm 1.04)$ & 0.001 \\
\hline Pulmonary metastases & $71.84(3.87 \pm 1.16)$ & $84.87(4.31 \pm 0.83)$ & $63.96(3.60 \pm 1.24)$ & $<0.001$ \\
\hline Shorter disease-free interval & $86.08(4.29 \pm 0.84)$ & $87.39(4.39 \pm 0.78)$ & $85.28(4.23 \pm 0.87)$ & 0.599 \\
\hline Omental metastases & $63.92(3.68 \pm 1.11)$ & $78.15(4.05 \pm 0.95)$ & $55.33(3.46 \pm 1.15)$ & $<0.001$ \\
\hline Pancreatic adenocarcinoma & $46.84(3.22 \pm 1.24)$ & $47.06(3.24 \pm 1.22)$ & $46.70(3.22 \pm 1.26)$ & 0.951
\end{tabular}

Case 2: a 45-year-old woman with epithelial ovarian cancer 36 months from optimal debulking and adjuvant chemotherapy with a single point of obstruction in the small bowel from carcinomatosis. She has three peritoneal implants, but no other metastatic disease.

\begin{tabular}{|lllll}
\hline Base scenario & $74.48(3.97 \pm 1.12)$ & $90.18(4.29 \pm 0.86)$ & $64.61(3.60 \pm 1.19)$ & $<0.001$ \\
\hline Ascites present & $57.24(3.41 \pm 1.19)$ & $74.11(3.81 \pm 1.04)$ & $46.63(3.16 \pm 1.21)$ & $<0.001$ \\
\hline Multiple areas of obstruction & $22.76(2.54 \pm 1.17)$ & $26.79(2.65 \pm 1.13)$ & $20.22(2.48 \pm 1.18)$ & 0.194 \\
\hline 2nd episode of obstruction & $24.48(2.63 \pm 1.14)$ & $25.00(2.63 \pm 1.07)$ & $24.16(2.65 \pm 1.18)$ & 0.871 \\
\hline Shorter disease-free interval & $47.59(3.24 \pm 1.13)$ & $50.00(3.29 \pm 1.03)$ & $46.07(3.22 \pm 1.18)$ & 0.514 \\
\hline Melanoma & $73.10(3.88 \pm 1.15)$ & $87.50(4.27 \pm 0.99)$ & $64.04(3.63 \pm 1.19)$ & $<0.001$ \\
\hline $\begin{array}{l}\text { Case 3: a 62-year-old woman with a carcinoid tumor } 48 \text { months from resection of an isolated mesenteric mass with a single point of obstruction in the jejunum from an } \\
\text { unresectable central mesenteric mass. }\end{array}$ & & & 0.008 \\
\hline Base scenario & $83.88(4.21 \pm 0.93)$ & $90.99(4.50 \pm 0.74)$ & $79.01(4.01 \pm 0.99)$ & $<0.001$ \\
\hline Stable hepatic metastases & $75.09(3.94 \pm 1.00)$ & $87.39(4.33 \pm 0.81)$ & $66.67(3.67 \pm 1.03)$ & 0.005 \\
\hline 2nd episode of obstruction & $44.69(3.22 \pm 1.11)$ & $54.95(3.41 \pm 1.03)$ & $37.65(3.08 \pm 1.15)$ & 0.248 \\
\hline Shorter disease-free interval & $32.97(2.82 \pm 1.23)$ & $36.94(2.91 \pm 1.25)$ & $30.25(2.76 \pm 1.21)$ & 0.04 \\
\hline Multiple areas of obstruction & $32.60(2.90 \pm 1.15)$ & $39.64(3.09 \pm 1.12)$ & $27.78(2.78 \pm 1.15)$ & \\
\hline
\end{tabular}

All patients were described as being otherwise healthy with good functional status. Patients had no signs of peritonitis or other indications for emergent surgery, although participants were informed that the obstruction would not resolve with conservative management. Responses reported as percent responding 'likely' or 'very likely' to offer an operation (mean response on the 5-point Likert scale \pm SD). Full case scenarios are shown in online supplemental file 1.

outcomes, including quality-of-life outcomes, for patients with MSBO. ${ }^{18}$ This information will help to study quality-of-life metrics in future research.

The heterogeneity of MSBO presentations has made this disease challenging to study. The wide range of clinical and quality-of-life outcomes above demonstrates the wide range of expectations after surgery for patients with MSBO. A current multicenter randomized trial to compare outcomes for patients with MSBO undergoing surgical and non-surgical management is ongoing. ${ }^{19}$ Randomization has been challenging, secondary to the wide range of patient factors in individual cases and clinician bias towards certain management. ${ }^{20}$ This study demonstrates the broad range of opinions and the clinical factors that contribute to differences in opinions. The heterogeneity of presented cases strengthens the findings of this study by reflecting an accurate depiction of this disease and the subsequent differences in management.

This study must be interpreted in the context of several limitations. First, this study is limited by the theoretical nature of these cases. Outcomes with either surgical or non-surgical management are unknowable. Current national practice patterns are not based on strong evidence at this time, so the responses in this study allow for an estimation of actual practice patterns. Future research should analyze a deeper understanding of the rationale behind surgeon choices. Second, this study is limited in scope by only asking participants whether an operation should be offered or not. This was done to limit the length of the survey and improve response rates, but in-depth qualitative research on this topic would be valuable. Third, the response rate to the survey was low. This is not uncommon in surveys sent to large email list serves. Providers more interested in this topic were likely more responsive to the survey request. Although these providers probably treat $\mathrm{MBO}$ more frequently than those who did not respond, there is some degree of selection bias. Finally, we did not survey a large cohort of general surgeons or colorectal surgeons, groups that sometimes manage these patients in some settings. Opinions of these other groups would be important to understand a more comprehensive view of this problem.

\section{CONCLUSIONS}

We identified wide variation in surgeon opinions towards treatment of patients with MSBO. Multiple clinical factors previously not well studied, including the number of sites of obstruction, recurrent MSBO, and disease-free intervals, impact surgeon decision-making when deciding on whether to offer surgical interventions. In addition, surgeon training and experience have a strong influence on the care a patient will be offered. As surgeons from many different subspecialties care for these patients, acute care surgery and surgical oncology training should have a greater emphasis on MSBO, an area of crossover between the two specialties. When possible, multidisciplinary teams consisting of experts in both oncology and acute surgical presentations should be involved in decision-making for patients with MSBO. Future research should focus on determining whether outcomes, both clinical and quality-of-life outcomes, differ between patients treated by surgical oncologists and acute care surgeons.

Acknowledgements We would like to thank the Society for Surgical Oncology (SSO), the Eastern Association for the Surgery of Trauma (EAST), and the American Society of Peritoneal Surface Malignancies (ASPSM) for their assistance with survey distribution. 
Contributors All authors were responsible for the conception of this study. JB performed data acquisition and analysis. All authors interpreted the data. JB created the initial manuscript draft and all authors contributed to subsequent review and editing of the manuscript. All authors provided final approval for this manuscript.

Funding This work was supported in part by the National Center for Advancing Translational Sciences of the National Institutes of Health under Award Number UL1TR002538

Disclaimer The content is solely the responsibility of the authors and does not necessarily represent the official views of the National Institutes of Health

Competing interests None declared.

Patient consent for publication Not required.

Ethics approval This study was approved by the University of Utah Institutional Review Board, approval ID 00126234. All participants were informed that consent was implied with survey completion.

Provenance and peer review Not commissioned; externally peer reviewed.

Data availability statement Data are available upon reasonable request. Data are available on reasonable request from the corresponding author.

Open access This is an open access article distributed in accordance with the Creative Commons Attribution Non Commercial (CC BY-NC 4.0) license, which permits others to distribute, remix, adapt, build upon this work non-commercially, and license their derivative works on different terms, provided the original work is properly cited, appropriate credit is given, any changes made indicated, and the use is non-commercial. See: http://creativecommons.org/licenses/by-nc/4.0/.

ORCID iD

Josh Bleicher http://orcid.org/0000-0001-6137-4426

\section{REFERENCES}

1 Lambert LA, Hendrix RJ. Palliative management of advanced peritoneal carcinomatosis. Surg Oncol Clin N Am 2018;27:585-602.

2 Tuca A, Guell E, Martinez-Losada E, Codorniu N. Malignant bowel obstruction in advanced cancer patients: epidemiology, management, and factors influencing spontaneous resolution. Cancer Manag Res 2012;4:159-69.

3 Franke AJ, Iqbal A, Starr JS, Nair RM, George TJ. Management of malignant bowel obstruction associated with Gi cancers. J Oncol Pract 2017;13:426-34.

4 Cousins S, Tempest E, DJ F. Surgery for the resolution of symptoms in malignant bowel obstruction in advanced gynaecological and gastrointestinal cancer (cochrane review). Cochrane Database Syst Rev 2000;4.

5 Paul Olson TJ, Pinkerton C, Brasel KJ, Schwarze ML. Palliative surgery for malignant bowel obstruction from carcinomatosis: a systematic review. JAMA Surg 2014;149:383-92.
6 National Audit of Small Bowel Obstruction Steering Group \& National Audit of Small Bowel Obstruction Collaborators. Outcomes following small bowel obstruction due to malignancy in the National audit of small bowel obstruction. Eur J Surg Oncol 2019.

7 Krouse RS. Malignant bowel obstruction. J Surg Oncol 2019;120:74-7.

8 Cauley CE, Panizales MT, Reznor G, Haynes AB, Havens JM, Kelley E, Mosenthal AC, Cooper Z. Outcomes after emergency abdominal surgery in patients with advanced cancer. J Trauma Acute Care Surg 2015;79:399-406.

9 Blair SL, Chu DZ, Schwarz RE. Outcome of palliative operations for malignant bowel obstruction in patients with peritoneal carcinomatosis from nongynecological cancer. Ann Surg Oncol 2001;8:632-7.

10 Aday LA, Cornelius LJ. Designing and conducting health surveys: a comprehensive guide. 3 edn. San Francisco CA, 2006

11 Barros AJD, Hirakata VN. Alternatives for logistic regression in cross-sectional studies: an empirical comparison of models that directly estimate the prevalence ratio. BMC Med Res Methodol 2003:3:1-13.

12 Sauer BC, Brookhart MA, Roy J, VanderWeele T. A review of covariate selection for non-experimental comparative effectiveness research. Pharmacoepidemiol Drug Saf 2013;22:1139-45

13 Norton EC, Dowd BE, Maciejewski ML. Marginal Effects - Quantifying the Effect of Changes in Risk Factors in Logistic Regression Models. JAMA - J Am Med Assoc 2018;320:84-5.

14 Bento JH, Bianchi ET, Tustumi F, Leonardi PC, Junior UR, Ceconello I. Surgical management of malignant intestinal obstruction: outcome and prognostic factors. Chirurgia 2019;114:343.

15 Bednarsch J, Czigany Z, Heise D, Zimmermann H, Boecker J, Ulmer TF, Neumann UP, Klink C. Influence of peritoneal carcinomatosis on perioperative outcome in palliative gastric bypass for malignant gastric outlet obstruction - a retrospective cohort study. World J Surg Oncol 2020;18:1-8.

16 Mooney SJ, Winner M, Hershman DL, Wright JD, Feingold DL, Allendorf JD, Neugut Al. Bowel obstruction in elderly ovarian cancer patients: a population-based study. Gynecol Oncol 2013;129:107-12.

17 Winner M, Mooney SJ, Hershman DL, Feingold DL, Allendorf JD, Wright JD, Neugut Al. Management and outcomes of bowel obstruction in patients with stage IV colon cancer: a population-based cohort study. Dis Colon Rectum 2013;56:834-43.

18 Baddeley E, Bravington A, Johnson M, Currow DC, Murtagh FE, Boland E, Obita G, Nelson A, Seddon K, Oliver A, et al. Development of a core outcome set to use in the research and assessment of malignant bowel obstruction: protocol for the RAMBO study. BMJ Open 2020;10:e039154.

19 SWOG. Cancer Research Network. SWOG Study S1316 Page. 2020. https://www. swog.org/swog-study-s1316-page.

20 Deutsch GB, Deneve JL, Al-kasspooles MF, Nfonsam VN, Gunderson CC, Secord $A A$, Rodgers $P$, Hendren S, Silberfein EJ, Grant $M$, et al. Intellectual equipoise and challenges: Accruing patients with advanced cancer to a trial randomizing to surgical or nonsurgical management (SWOG S1316). Am J Hosp Palliat Med 2019:1-7 